\title{
Radiometric calibration of the in-flight blackbody calibration system of the GLORIA interferometer
}

\author{
C. Monte ${ }^{1}$, B. Gutschwager ${ }^{1}$, A. Adibekyan ${ }^{1}$, M. Kehrt ${ }^{1}$, A. Ebersoldt ${ }^{2}$, F. Olschewski ${ }^{3}$, and J. Hollandt ${ }^{1}$ \\ ${ }^{1}$ Physikalisch-Technische Bundesanstalt, Abbestraße 2-12, 10587 Berlin, Germany \\ ${ }^{2}$ Karlsruhe Institute of Technology, 76344 Eggenstein-Leopoldshafen, Germany \\ ${ }^{3}$ University of Wuppertal, Atmospheric Physics, 42119 Wuppertal, Germany
}

Correspondence to: J. Hollandt (joerg.hollandt@ ptb.de)

Received: 15 May 2013 - Published in Atmos. Meas. Tech. Discuss.: 14 June 2013

Revised: 29 October 2013 - Accepted: 12 November 2013 - Published: 6 January 2014

\begin{abstract}
GLORIA (Gimballed Limb Observer for Radiance Imaging of the Atmosphere) is an airborne, imaging, infrared Fourier transform spectrometer that applies the limbimaging technique to perform trace gas and temperature measurements in the Earth's atmosphere with three-dimensional resolution. To ensure the traceability of these measurements to the International Temperature Scale and thereby to an absolute radiance scale, GLORIA carries an on-board calibration system. Basically, it consists of two identical large-area and high-emissivity infrared radiators, which can be continuously and independently operated at two adjustable temperatures in a range from $-50^{\circ} \mathrm{C}$ to $0{ }^{\circ} \mathrm{C}$ during flight. Here we describe the radiometric and thermometric characterization and calibration of the in-flight calibration system at the Reduced Background Calibration Facility of the PhysikalischTechnische Bundesanstalt. This was performed with a standard uncertainty of less than $110 \mathrm{mK}$. Extensive investigations of the system concerning its absolute radiation temperature and spectral radiance, its temperature homogeneity and its short- and long-term stability are discussed. The traceability chain of these measurements is presented.
\end{abstract}

\section{Introduction}

The Gimballed Limb Observer for Radiance Imaging of the Atmosphere (GLORIA) (Friedl-Vallon et al., 2014; Riese et al., 2014) is an airborne, imaging Fourier Transform Spectrometer (FTS) that utilizes the infrared limb-imaging technique to provide trace gas measurements in the Upper Troposphere-Lower Stratosphere (UTLS) region with unrivalled three-dimensional spatial resolution. The highly dynamic structure and chemical composition of the UTLS play an essential role in the Earth's climate system, causing prominent changes in the surface temperature via changes in the atmospheric radiative forcing (Solomon et al., 2010; Riese et al., 2012). To ensure traceable and sufficiently accurate measurements of the crucial parameters, i.e. atmospheric temperature and trace gas distributions, GLORIA applies a sophisticated in-flight blackbody calibration system (Olschewski et al., 2013). It is based on two identical large-area and high-emissivity infrared radiators, which can be continuously and independently operated at two adjustable reference temperatures in the range of the ambient atmospheric temperature. With these two GLORIA BlackBodies (GBB-C and GBB-H), radiometric in-flight calibration sequences are regularly performed between the atmospheric measurement sequences. The two blackbodies are named GBB-C (cold) and GBB-H (hot) for identification and due to the typical operation at well-separated temperatures $10 \mathrm{~K}$ below and $30 \mathrm{~K}$ above ambient temperature.

The required uncertainties of the spectral radiance and the radiation temperature of the GBBs follow from the target uncertainties of the retrieved temperature and trace gas distributions. From these results an intended uncertainty of atmospheric spectral radiance measurements with GLORIA of better than $3 \%$ as a minimum requirement and a target uncertainty of $1 \%$ (Olschewski et al., 2013; ESA, 2012). Assuming a linear instrument response, a two-point calibration is applied during flight by operating the GBBs at two different, well-defined temperatures. Hence, to achieve the target uncertainty the spectral radiance of the individual GBBs 


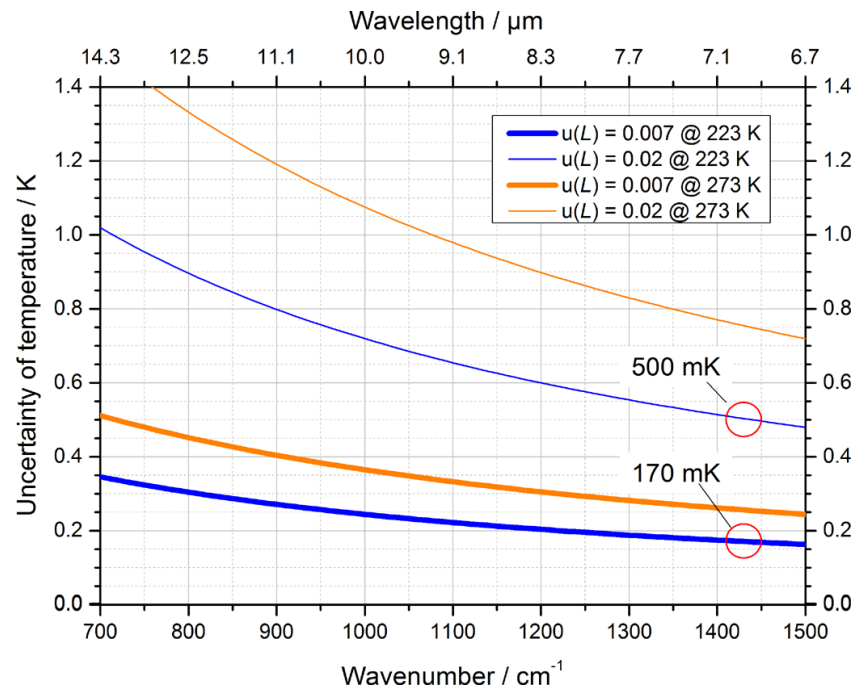

Fig. 1. Relationship between radiance uncertainty and radiation temperature uncertainty for the two extreme operation temperatures of the GBBs $\left(-50^{\circ} \mathrm{C}\right.$ and $\left.0{ }^{\circ} \mathrm{C}\right)$ and the two uncertainty levels 0.67 and $2 \%$ corresponding to GLORIA's target uncertainty of $1 \%$ and minimum requirement uncertainty of $3 \%$.

has to be known with a relative standard uncertainty below $0.67 \%$ (assuming the worst case that the uncertainties of both blackbodies add equally) or, expressed in temperature, their radiation temperature has to be calibrated with an uncertainty of better than $170 \mathrm{mK}$ traceable to the International Temperature Scale of 1990 (ITS-90). The spectral relationship between radiance uncertainty and radiation temperature uncertainty is illustrated in Fig. 1 for the two extreme operating temperatures of the GBBs $-50^{\circ} \mathrm{C}\left(\right.$ GBB-C) and $0{ }^{\circ} \mathrm{C}$ (GBB-H) and the two uncertainty levels $0.67 \%$ and $2 \%$ corresponding to the target uncertainties of $1 \%$ and minimum requirement of $3 \%$. This relationship leads at the shortest relevant wavelength of $7 \mu \mathrm{m}$ and a temperature of $-50^{\circ} \mathrm{C}$ to radiation temperature uncertainties of $170 \mathrm{mK}$ and $500 \mathrm{mK}$, respectively.

In addition, the emissivity of the GBBs needs to be as high as possible to avoid uncertainties caused by reflected radiation from a non-isothermal environment.

To achieve the required small uncertainty in the surface radiation temperature of the GBBs, a temperature measurement via contact thermometers and applying appropriate corrections for temperature gradients and inhomogeneities as well as for non-ideal emissivity is insufficient. Only a direct measurement of their surface radiation temperature and spectral radiance in comparison to blackbody radiation from high-quality cavity radiators linked to the primary standards of temperature radiation yields sufficiently small uncertainties and strict traceability to the ITS-90. Following this scheme, a rigid and thorough calibration procedure has been established to regularly characterize and calibrate the GBBs traceable to the national standards of tempera- ture at the Physikalisch-Technische Bundesanstalt (PTB), the national metrology institute of Germany. From December 2010 to January 2013 the GBBs were investigated and calibrated at the Reduced Background Calibration Facility (RBCF) (Monte et al., 2009a, b) of PTB in three measurement campaigns before and after their flight operations. The RBCF allows for the calibration of spectral radiance and radiation temperature under environmental conditions similar to those during flight operation. The calibration is performed by direct comparison of the GBBs with reference cavity blackbody radiators (emissivity $>0.9997$ ) of known radiation temperature. For the measurement of spectral radiance this comparison is realized with an FTS, for radiation temperature with a broadband radiation thermometer as the transfer instruments. The GBBs have been fully characterized for their spatially (whole aperture) and spectrally ( $7 \mu \mathrm{m}$ to $13 \mu \mathrm{m}$ ) resolved radiation properties in terms of radiation temperature traceable to the ITS-90.

\section{Instrumentation}

\subsection{GLORIA}

GLORIA is a joint project of the Research Centre Jülich and the Karlsruhe Institute of Technology, Germany. The GLORIA instrument (Fig. 2) is an airborne imaging Michelson FTS which utilizes the newly developed tomographic limb-imaging technique that provides three-dimensional observations of multiple trace gases, aerosols and clouds in the UTLS with unprecedented resolution (Ungermann et al., 2011). GLORIA successfully passed its test flight campaign with the Russian high-altitude aircraft M55-Geophysica during the ESA Sounder Campaign ESSenCe in Kiruna, Sweden, in December 2011. GLORIA was developed particularly for operation in the belly pod of the new German research aircraft, the High Altitude and LOng Range Research Aircraft (HALO), and successfully completed its first scientific deployment during the TACS/ESMVal campaign (Transport and Composition in the UTLS/Earth System Model Validation) on HALO in September 2012. Several HALO campaigns will follow and further Geophysica campaigns will be proposed at EU level.

The GLORIA instrument and its scientific capabilities are described in detail in Friedl-Vallon et al. (2014) and Riese et al. (2014). In brief, a two-lens aspherical optics system is used to image the actual atmospheric conditions via an FTS on a two-dimensional detector array for detailed infrared limb observations in emission. The detector array consists of $128 \times 128$ single detector elements providing over $16000 \mathrm{si}-$ multaneous spectrally resolved limb views in a spectral range from $770 \mathrm{~cm}^{-1}$ to $1400 \mathrm{~cm}^{-1}$ (13 $\mu \mathrm{m}$ to $\left.7 \mu \mathrm{m}\right)$. The gimbal mount, which stabilizes the line of sight during flight, also allows for pointing at azimuth angles between $45^{\circ}$ and $135^{\circ}$ with respect to the flight direction, as well as nadir viewing. 

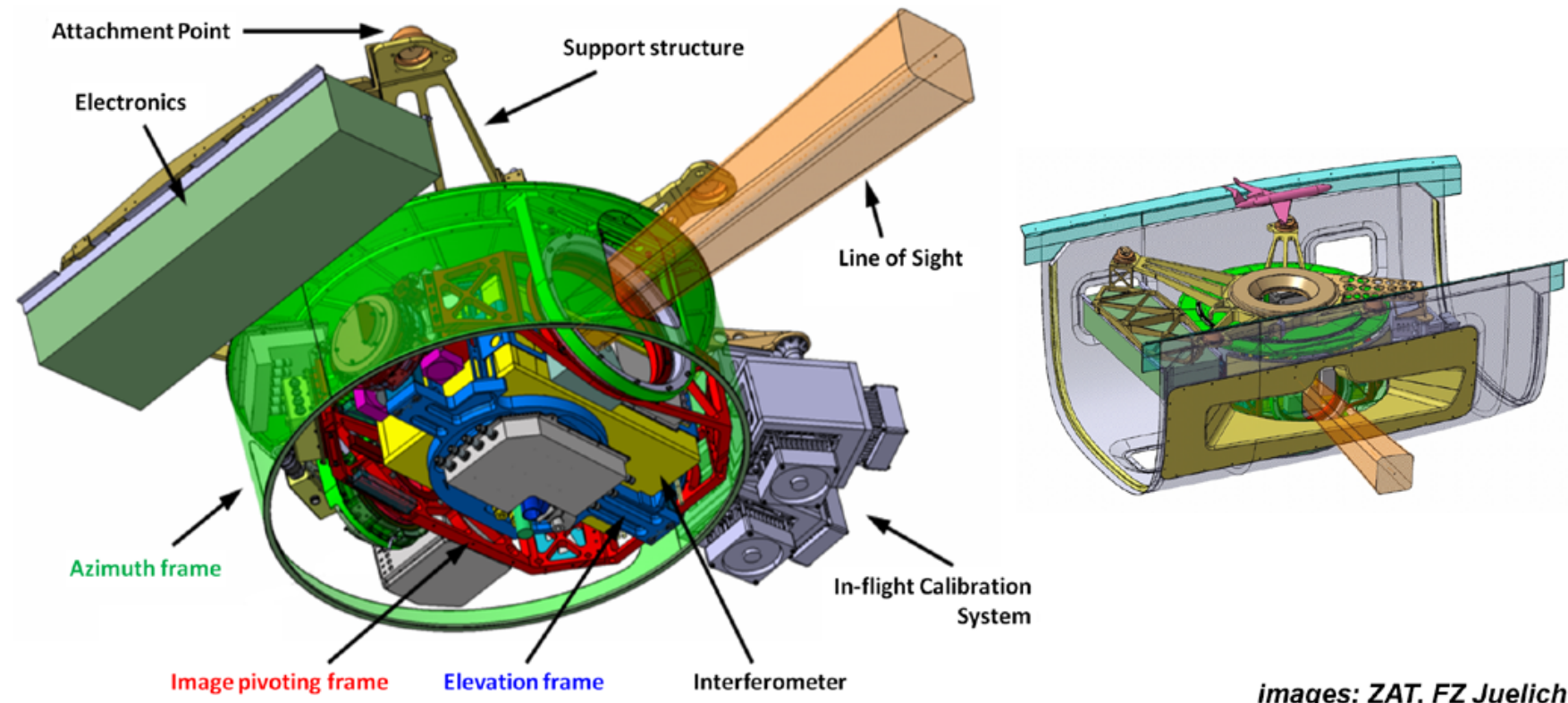

Fig. 2. Left: Gimbal-mounted GLORIA instrument with its in-flight calibration system. Right: GLORIA in the belly pod of a research airplane.

GLORIA delivers images of the atmospheric limb, within a field of view of $4.07^{\circ} \times 4.07^{\circ}$, which extends from tangent altitudes of $4 \mathrm{~km}$ to about flight level. The gimbal ability is also used to regularly align the FTS with its in-flight calibration sources.

Further to the required $1 \%$ uncertainty in the absolute knowledge of the GLORIA spectral responsivity, the specific data evaluation procedure of limb-sounding requires an uncertainty for the relative responsivity of adjacent lines of pixels on the detectors of even $0.1 \%$. This implies strong demands on the radiance homogeneity of the GBBs and their spatially resolved calibration. Above all, GLORIA served as the proof of concept for the infrared limb sounder of PREMIER (PRocess Exploitation through Measurements of Infrared and Millimetre-wave Emitted Radiation), which has been one of ESA's candidate Earth Explorer Core Missions (ESA, 2008).

\subsection{The GLORIA calibration system}

The GLORIA calibration system has been designed, built and laboratory-tested by the Department of Atmospheric Physics at the University of Wuppertal, Germany. Its control electronics were developed and built by the Institute for Data Processing and Electronics of Karlsruhe Institute of Technology. The design and thermal performance of the calibration system is described in detail in Olschewski et al. (2013). Throughout the deployment of GLORIA in the ESSenCe and TACS/ESMVal campaigns, the GBBs have been successfully operated and applied for calibration.
The actual range of reference temperatures for the twopoint calibration of GLORIA has been established in an optimization process under ideal metrological aspects and practical considerations of its technical realization during flight. An ideal measurement of the detector offset, which is generated by the instrument's self-emission, would require a "zero-emission" source, which is a source at $0 \mathrm{~K}$. However, in practice, a reference temperature below ambient temperature bears the risk of water or ice building up on the emitting surface and thus significantly changing the surface temperature and emissivity. To frame the radiance levels that occur during measurements in the UTLS and to define temperatures which are practically feasible within reasonable operating times, the range of reference temperatures was fixed to at least $10 \mathrm{~K}$ below and $30 \mathrm{~K}$ above ambient temperature, i.e. the temperature of the GLORIA instrument compartment. The temperatures inside the instrument compartment are typically $20 \mathrm{~K}$ to $30 \mathrm{~K}$ above the temperature outside the airplane. In the UTLS this results in reference temperatures in the range from about $-50{ }^{\circ} \mathrm{C}$ to $0^{\circ} \mathrm{C}$ for the cold (GBB-C) and the warm (GBB-H) GLORIA blackbody.

The major radiometric and thermometric requirements on the GLORIA calibration system (Olschewski et al., 2013) are summarized as follows:

- Minimum size of radiating area $102 \mathrm{~mm} \times 102 \mathrm{~mm}$.

- Temperature of the GBB-C at least $10 \mathrm{~K}$ below ambient temperature.

- Temperature difference between the GBB-C and GBB-H at least $40 \mathrm{~K}$. 

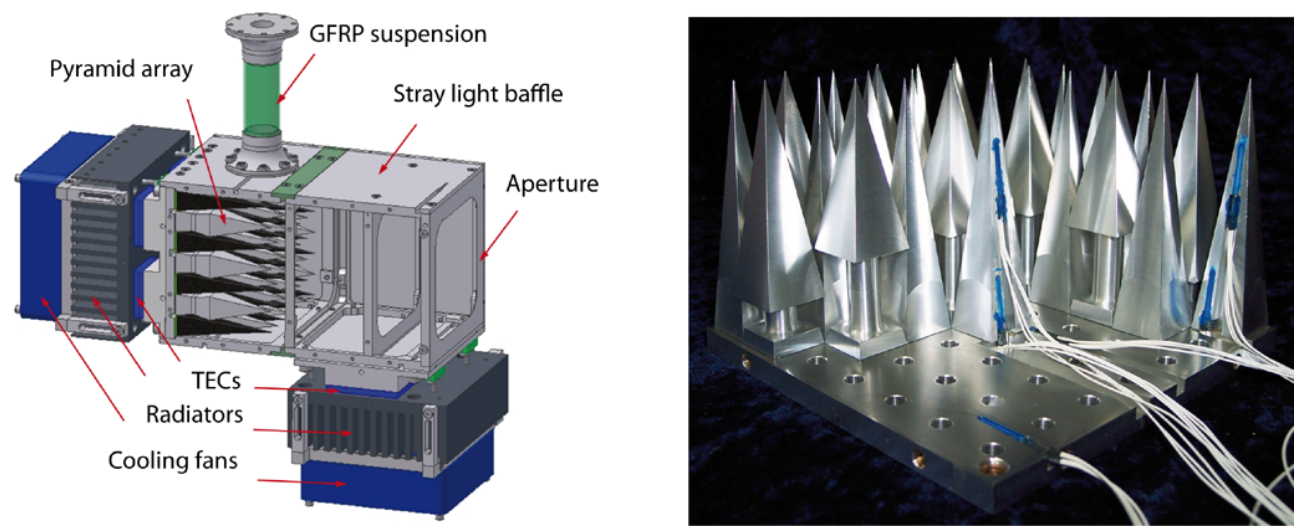

Fig. 3. Left: schematic diagram of a GLORIA blackbody; right: partly assembled prototype version of the pyramid array which forms the radiating optical surface of a GLORIA blackbody. Three different types of uncoated pyramids are noticeable. The position of platinum resistance thermometers in the pyramids and the base plate are marked in blue.

- Standard uncertainty of surface radiation temperature less than $100 \mathrm{mK}$.

- Short-term temperature stability better than $25 \mathrm{mK} \mathrm{min}^{-1}$.

- Temperature homogeneity better than $150 \mathrm{mK}$ over full aperture.

The limited resources in weight and electrical power provided in the instrument compartment of the aircraft, the harsh and rapidly changing environmental conditions during flight and the demanding calibration requirements of GLORIA meant a major challenge for the design and operation of the calibration system.

The concept of one of the two identical GBBs is shown in Fig. 3. The radiating optical surface of a GBB spans $126 \mathrm{~mm} \times 126 \mathrm{~mm}$ and consists of an array of $7 \times 7$ single pyramids made of aluminium. The pyramids as well as the casing are varnished with NEXTEL Velvet Coating 811-21, yielding a surface emissivity of 0.967 in the range from 5 to $12 \mu \mathrm{m}$ (Lohrengel and Todtenhaupt, 1996). To avoid direct reflections by surfaces perpendicular to the line of sight, three types of pyramids are used with different square bases at different height levels. Thus light traps are formed at the bottom of the pyramids to prevent direct back reflections. Calculations of the geometry factors of the pyramid array in a medium-sized box according to Howell (2010) and their weighting with the surface emissivity of the NEXTEL coating resulted in an effective emissivity of the GBBs of 0.9996 (Olschewski et al., 2013).

For temperature monitoring and control of the GLORIA calibration system, each GBB is equipped with 24 Platinum Resistance Thermometers (PRTs) of the type DIN B/10 $(100 \Omega)$ with a nominal temperature uncertainty of $30 \mathrm{mK}$ at $0{ }^{\circ} \mathrm{C}$. Five pyramids of each GBB radiating optical surface are equipped with a PRT close to the apex and another PRT close to the base. Figure 4 illustrates that these pyramids are

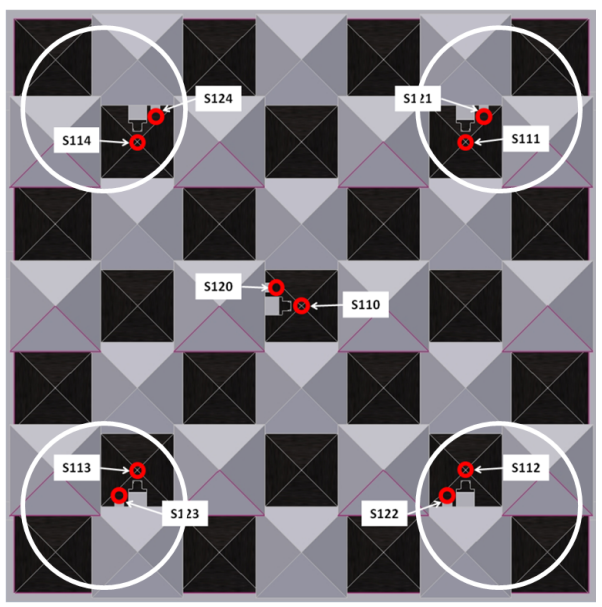

Fig. 4. Location of the 49 pyramids and the 10 platinum resistance thermometers (S110 to S114 and S120 to S124) on the radiating optical surface of a GLORIA blackbody. The white circles represent the field of view of the corner pixels of the GLORIA detector array.

positioned close to the corners and in the centre of the pyramid array. During operation, individual temperature control in four sectors of the optical surface is performed with the mean value of the apex and the base temperature of the respective corner pyramid as the control value. The radiometric calibration was performed with respect to the temperatures of these 10 PRTs monitoring the temperature of the pyramid field. Fourteen more PRTs are used for monitoring the temperatures of the casing and the cooling surfaces of each GBB.

Operating the GBBs at temperatures below and above ambient temperature is achieved by Thermo-Electric Coolers (TECs), which provide the options of cooling and heating by simply switching the direction of the electrical current. For the temperature control of the radiating optical surface, an assembly of four two-stage TECs (type Peltron 128A0020) 


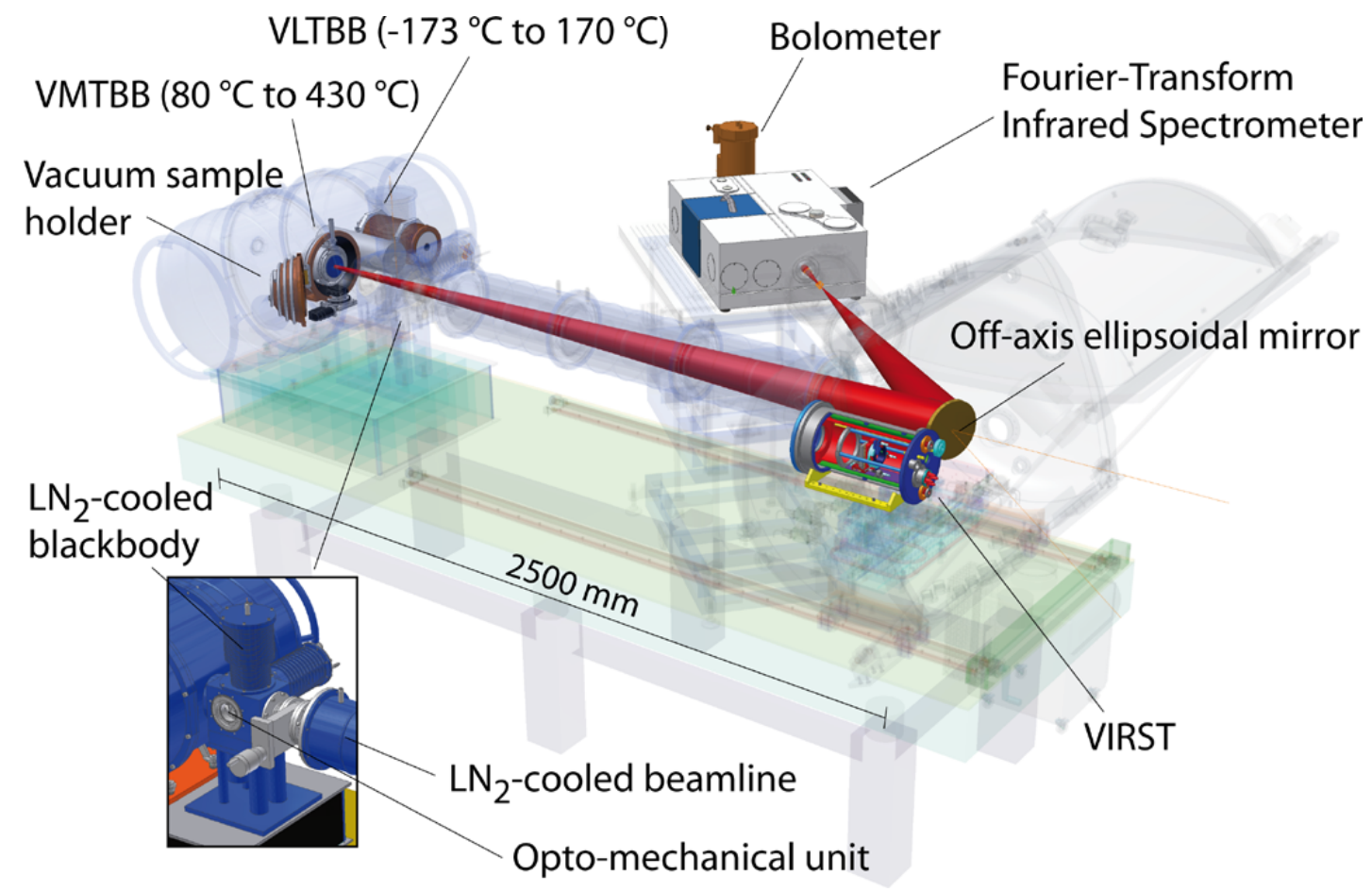

Fig. 5. Transparent view of the Reduced Background Calibration Facility to illustrate the position of the source chamber with the reference blackbodies VLTBB and VMTBB as well as the vacuum sample holder for emissivity measurements; the position of the opto-mechanical unit, with the folding mirrors, the chopper and the liquid-nitrogen-cooled reference blackbody; the position of the beam line; and the position of the detector chamber with the radiation thermometer VIRST and an ellipsoidal mirror guiding the radiation into a Fourier transform spectrometer.

is used with each GBB. The casing and the baffle system are each cooled by one TEC (type Peltron 128A2427) (Fig. 3).

Both GBBs are suspended to the GLORIA instrument by glass-fibre-reinforced plastic tubes for thermal decoupling and are covered with polystyrene foam sheets to reduce the thermal influence of the environment.

\subsection{The reduced background calibration facility}

The RBCF of PTB serves as a facility for the measurement of spectral radiance and radiation temperature of radiation sources and the signal temperature characteristic of radiation thermometers under reduced infrared background radiation in a temperature range from $-170{ }^{\circ} \mathrm{C}$ to $430^{\circ} \mathrm{C}$ traceable to the ITS-90. Furthermore, it allows the spectrally and angularly resolved measurement of the spectral emissivity of samples from $-40{ }^{\circ} \mathrm{C}$ to $600{ }^{\circ} \mathrm{C}$. Measurements can be performed in air, under the pressure conditions of the upper atmosphere, and in vacuum.

\subsubsection{Setup and calibration procedure}

The setup of the RBCF and its radiometric application for source and detector calibrations as well as emissivity measurements are described in detail in Monte et al. (2009a, b). Its major vacuum components are a source chamber, accommodating the blackbody reference radiators; an optomechanical unit, allowing folding mirrors and an optical chopper to be inserted into the line of sight; a beam line; and a detector chamber, which houses the Vacuum Infrared Standard Radiation Thermometer (VIRST). Additionally, an off-axis ellipsoidal mirror in the detector chamber allows the guiding of the radiation from the source chamber into a vacuum FTS for spectrally resolved measurements (Fig. 5). All optical baffles, the gold-coated folding mirrors and chopper, and the walls of the beam line are cooled by means of liquid nitrogen to temperatures below $-150^{\circ} \mathrm{C}$.

Three different variable-temperature blackbodies serve as reference standards in the source chamber: the Vacuum LowTemperature BlackBody (VLTBB) (Morozova et al., 2008) from $-173^{\circ} \mathrm{C}$ to $177^{\circ} \mathrm{C}$, the Vacuum Medium-Temperature BlackBody (VMTBB) (Morozova et al., 2010) from $80^{\circ} \mathrm{C}$ to $430^{\circ} \mathrm{C}$ and the Liquid-operated variable-temperature BlackBody (LBB) (Monte et al., 2013) from $-70^{\circ} \mathrm{C}$ to $80^{\circ} \mathrm{C}$. In addition, a liquid-nitrogen-cooled reference blackbody is mounted on the top of the opto-mechanical unit as a "zero" reference source. In general, the source chamber is operated with the VLTBB and the VMTBB inside. In this case there is additional room in the source chamber to accommodate either the sample holder for emissivity measurements or a 


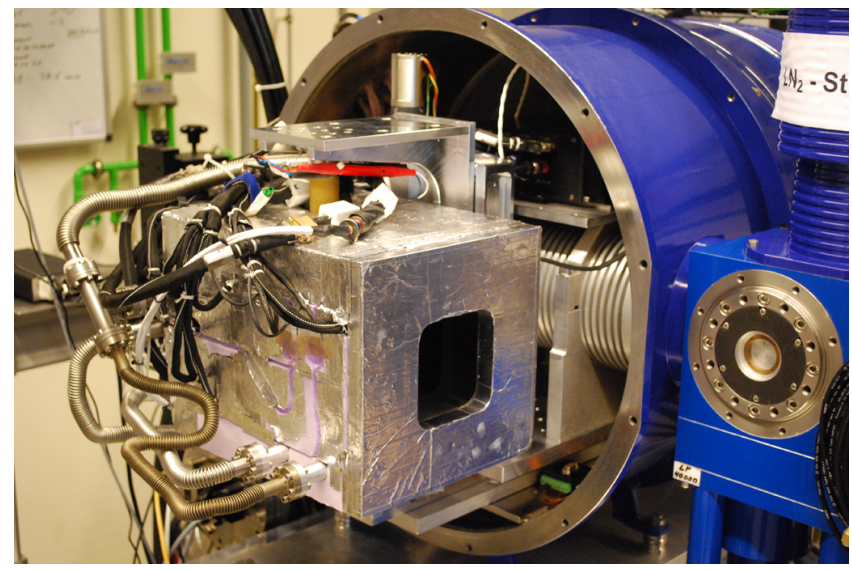

Fig. 6. View of the opened source chamber of the Reduced Background Calibration Facility. One of the GLORIA blackbodies is installed for calibration. To the right of the GLORIA blackbody, the reference blackbody VLTBB can be seen. Attached to the source chamber, the opto-mechanical unit with the liquid-nitrogen-cooled blackbody on top can be partially seen.

radiation source under calibration. Due to their size and the requirement to map their whole aperture in two dimensions, the GBBs had to be calibrated one after the other in the source chamber and a source chamber configuration had to be realized with only the VLTBB and one GBB at a time inside (Fig. 6).

The calibration of the GBBs was performed by direct comparison of each GBB to the reference blackbody VLTBB via VIRST and via the vacuum FTS. The comparisons were performed under dry nitrogen pressure of $100 \mathrm{mbar}$ and under vacuum. A horizontal translation stage allowed the alternate positioning of the GBB and the VLTBB on the Line Of Sight (LOS) between the source- and detector chamber, which corresponds with the centre of the cooled beam line. Attaching the GBB to an additional vertical translation stage allowed every part of its radiating optical surface to be placed on the LOS. As VIRST and the off-axis ellipsoidal mirror are also placed on a horizontal translation stage in the detector chamber, a direct short-term interchange between both comparison instruments was possible.

The radiation thermometer VIRST is described in detail in Gutschwager et al. (2008, 2009). VIRST is a stand-alone transfer radiation thermometer which can be operated inside a vacuum chamber, attached to a vacuum chamber or, when equipped with an antireflection-coated zinc selenide window, in air. It features a vacuum-insulated and thermally stabilized housing, a selected thermopile detector, dedicated readout electronics and an aspheric germanium lens. A band-pass filter in front of the detector limits the sensitive spectral range from $8 \mu \mathrm{m}$ to $14 \mu \mathrm{m}$. VIRST achieves a temperature resolution or Noise-Equivalent Temperature Difference (NETD) of better than $10 \mathrm{mK}$ at $0{ }^{\circ} \mathrm{C}$.

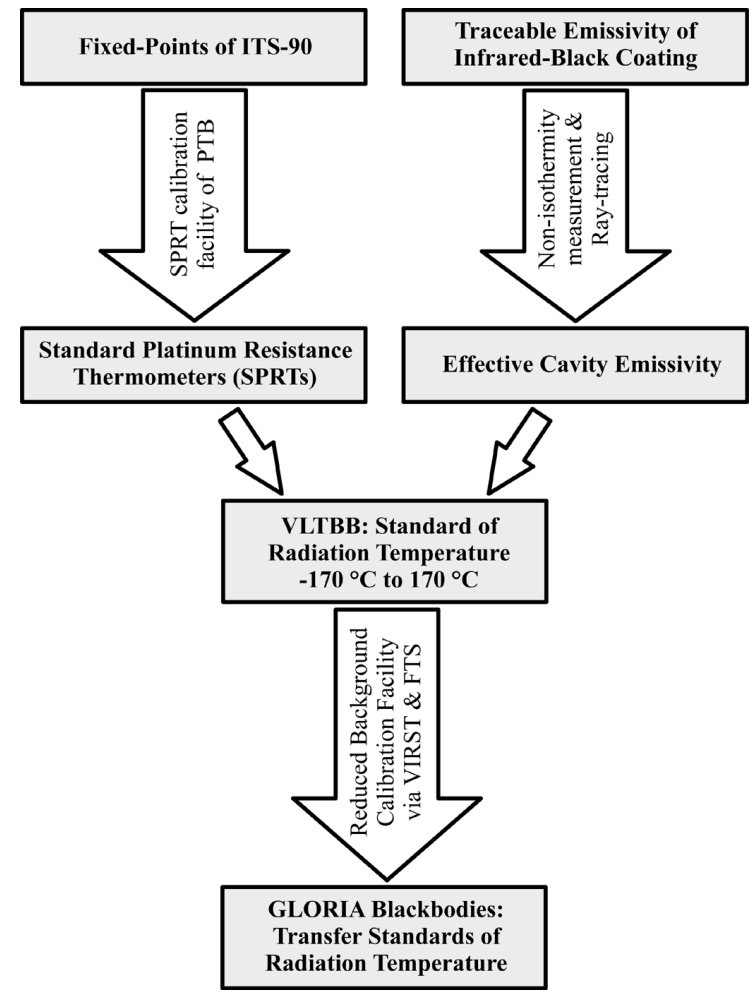

Fig. 7. Calibration chain diagram of the GLORIA blackbodies.

The vacuum FTS is a commercial system of the type BRUKER VERTEX 80v which allows for spectrally resolved measurements from $0.4 \mu \mathrm{m}$ to $1400 \mu \mathrm{m}$. For high stability the system applies a linear air-bearing scanner and has been additionally temperature stabilized to better than $100 \mathrm{mK}$.

For the characterization and calibration of the GBBs, two measurement schemes have been applied:

- Using VIRST, radiation temperatures of the optical surface from $-50^{\circ} \mathrm{C}$ to $0^{\circ} \mathrm{C}$ have been measured in temperature steps of $5^{\circ} \mathrm{C}$ by direct comparison to the radiation temperature of the VLTBB. These measurements provide the calibration of the radiation temperature-resistance characteristics of the GLORIA BB PRTs. The field of view of VIRST on the optical surface of the GBBs is $10 \mathrm{~mm}$ in diameter. With VIRST spatially resolved temperature measurements have been performed over the full aperture of the optical surface. In addition, VIRST measured the shortterm stability of the GBBs.

- Using the vacuum FTS, spectrally resolved radiance measurements of the optical surface have been performed from $7 \mu \mathrm{m}$ to $16 \mu \mathrm{m}$ by direct comparison to the spectral radiance of the VLTBB. The field of view of the vacuum FTS on the optical surface of the GBBs is $18 \mathrm{~mm}$ in diameter. Measurements have been 


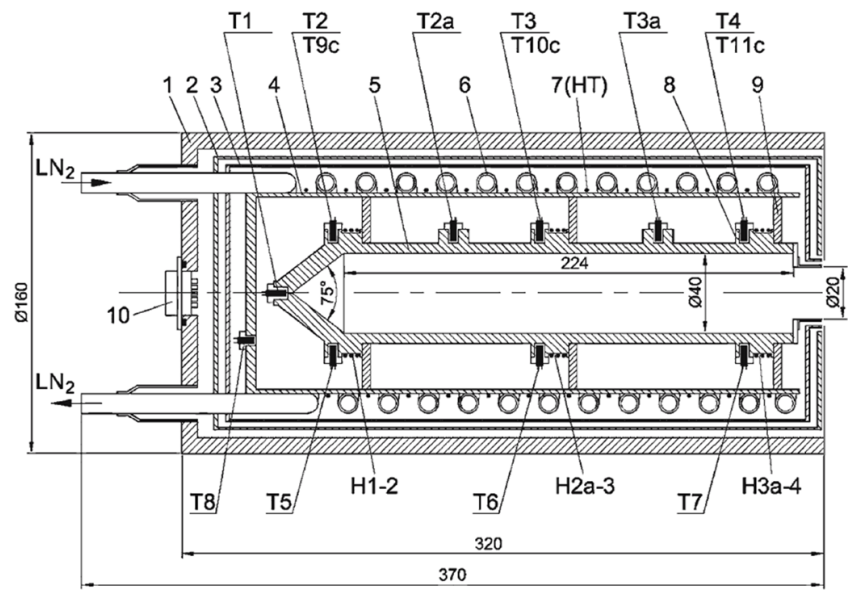

Fig. 8. Schematic diagram of the vacuum low-temperature blackbody: 1 - body of the VLTBB, 2 - second radiation shield, 3 - first radiation shield, 4 - cryo-shroud, 5 - cavity, 6 - cryo-shroud heat exchanger, 7 - cryo-shroud heater, 8 - ring-shaped enhancement of the cavity, 9 - heat link, 10 - electrical connector.

performed at $-50^{\circ} \mathrm{C}$ and $0{ }^{\circ} \mathrm{C}$ for the three different pyramid types on the optical surface.

So far three calibration campaigns have been performed with the GBBs at the RBCF: in December 2010, about one year before the maiden flight of GLORIA; in January 2012 shortly after its successful test flight with the Geophysica during the ESA Sounder Campaign ESSenCe; and in January 2013, about four months after its first scientific campaign with HALO during the TACS/ESMVal campaign.

\subsubsection{Traceability chain and uncertainty}

The calibration of the GBBs is traceable to the VLTBB, which is a calibration standard of radiation temperature and spectral radiance and is linked to the ITS-90 via its calibrated PRTs (Fig. 7). The design, thermal performance and effective emissivity of the VLTBB are described in detail in Morozova et al. (2008). In brief, the VLTBB consists of a cavity with three heat links, three independently controlled electrical heating zones along the cavity, 13 PRTs, a cryoshroud with a heat exchanger operating with liquid nitrogen, an electrical heater around the cryo-shroud, and two successive radiation shields (Fig. 8). The cylindrical cavity is made of oxygen-free copper $40 \mathrm{~mm}$ in diameter and $250.6 \mathrm{~mm}$ in length with a conical bottom and coated with black Aeroglaze Z306. The surface temperature of the cavity is monitored with nine PRTs selected for stability and calibrated traceable to the ITS-90 at PTB, while four fastresponse PRTs are used to control the cavity and shroud temperature.

The basic parameters and performance of the VLTBB, as derived from measurements, are given in Table 1 (Morozova et al., 2008; Monte et al., 2013).

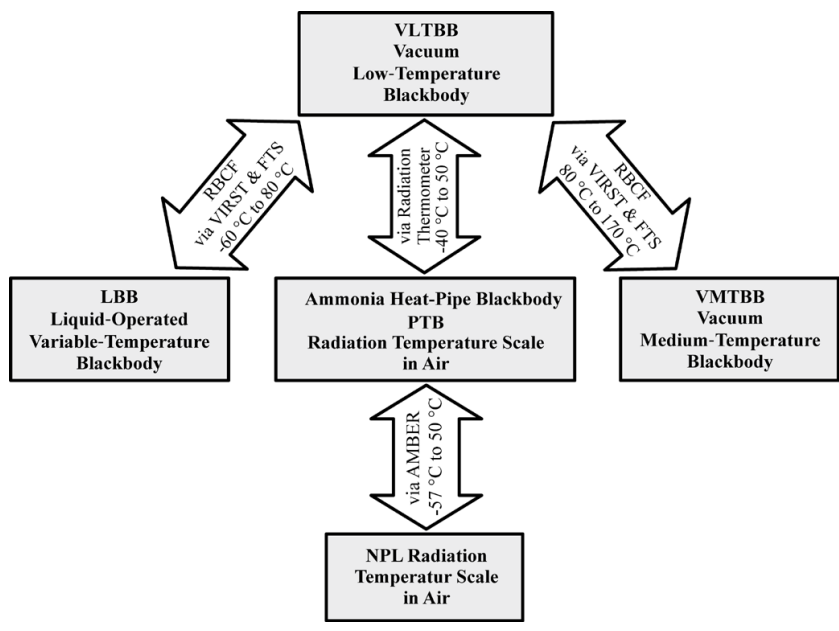

Fig. 9. Comparisons of the VLTBB with other radiation temperature standards in the context of the radiometric calibration of the GLORIA blackbodies.

The uncertainty budget of the VLTBB is given in Tables 2 and 3. It is based on the uncertainty of the PRT temperature measurement and the uncertainty of the nonisothermal effective cavity emissivity. PRT temperature uncertainties include the PRT calibration uncertainty at PTB traceable to ITS-90, the stability of calibration over time, and the type A uncertainty of PRT temperature measurement during comparison measurements with the VLTBB (JCGM, 2008). For the uncertainty of the effective cavity emissivity, the emissivity of the cavity wall coating has been measured at PTB (Monte and Hollandt, 2010a, b). Additionally, the nonisothermality along the cavity wall has been measured by PRTs for all relevant temperatures of the VLTBB. Isothermal and non-isothermal effective cavity emissivities have been calculated with the blackbody emissivity modelling program STEEP 3 (Prokhorov, 1998, 2013). STEEP calculations have been performed for the observation geometry of VIRST over the relevant wavelength range of the GBBs.

The overall standard uncertainty $(k=1$, confidence level $68.3 \%$ ) of the radiation temperature of the VLTBB at $-50{ }^{\circ} \mathrm{C}(223 \mathrm{~K})$ is $51 \mathrm{mK}$ at $10 \mu \mathrm{m}$ and $67 \mathrm{mK}$ at $14 \mu \mathrm{m}(\mathrm{Ta}-$ ble 3 ). Thus the VLTBB meets the requirements for the calibration of the GLORIA in-flight calibration system.

Several comparisons of the radiation temperature of the VLTBB with other radiation temperature standards were performed to confirm its temperature uncertainty by independent measurements (Fig. 9). The VLTBB was compared to the $\mathrm{LBB}$ at $-60^{\circ} \mathrm{C}, 0^{\circ} \mathrm{C}$ and $80^{\circ} \mathrm{C}$ via VIRST and via the vacuum FTS in the RBCF. All measurements showed good agreement between both blackbodies, well within the extended uncertainty $(k=2$, confidence level $95.5 \%)$ of the comparison of $130 \mathrm{mK}$ (Monte et al., 2013). Figure 10 gives the difference in radiation temperature of the VLTBB and 
Table 1. Basic parameters and performance of the VLTBB.

\begin{tabular}{ll}
\hline Range of radiation temperature $/{ }^{\circ} \mathrm{C}$ & -173 to 177 \\
Stability of PRT temperature $/ \mathrm{mK}$ & $<5$ (after settling time) \\
Stability of radiation temperature $/ \mathrm{mK}$ & $<30$ (after settling time) \\
Normal effective emissivity & $>0.9997$ \\
Cavity diameter $/ \mathrm{mm}$ & 40 \\
Cavity length $/ \mathrm{mm}$ & 250 \\
Outer aperture diameter $/ \mathrm{mm}$ & 20 \\
Shape of cavity bottom & $75^{\circ}$ outer cone \\
Overall dimensions of VLTBB diameter $/ \mathrm{mm} \times$ length $/ \mathrm{mm}$ & $200 \times 450$ \\
Temperature differences along the cavity $/ \mathrm{mK}$ & $<20$ (after settling time) \\
Settling time $(300 \mathrm{~K}$ up to $450 \mathrm{~K}) / \mathrm{min}$ & $<30$ \\
Settling time $(300 \mathrm{~K}$ down to $100 \mathrm{~K}) / \mathrm{min}$ & $<60$ \\
Ambient temperature range for operation $/{ }^{\circ} \mathrm{C}$ & 15 to 30 \\
Temperature of the outer wall of the VLTBB $/{ }^{\circ} \mathrm{C}$ & 15 to 40 \\
Application & in vacuum chamber \\
Cavity wall coating & Aeroglaze Z306 \\
Mass of VLTBB $/ \mathrm{kg}$ & $<15$ \\
\hline
\end{tabular}

Table 2. Uncertainty components $u(k=1)$ of the radiation temperature of the VLTBB.

\begin{tabular}{|c|c|c|c|c|c|c|c|c|}
\hline \multirow[b]{2}{*}{$t /{ }^{\circ} \mathrm{C}$} & \multicolumn{5}{|c|}{ Emissivity uncertainty (non-isothermal) $u_{\epsilon} / \mathrm{K}$} & \multirow{2}{*}{$\begin{array}{c}\text { PRT } \\
\text { noise } \\
u_{r} / \mathrm{K}\end{array}$} & \multirow{2}{*}{$\begin{array}{c}\text { PRT } \\
\text { stability } \\
u_{n} / \mathrm{K}\end{array}$} & \multirow{2}{*}{$\begin{array}{c}\text { PRT } \\
\text { calibration } \\
\text { uncertainty } \\
u_{\mathrm{Pt}} / \mathrm{K}\end{array}$} \\
\hline & $4.8 \mu \mathrm{m}$ & $6.7 \mu \mathrm{m}$ & $9.9 \mu \mathrm{m}$ & $12.2 \mu \mathrm{m}$ & $14.1 \mu \mathrm{m}$ & & & \\
\hline-80 & 0.025 & 0.009 & 0.009 & 0.009 & 0.034 & 0.001 & 0.064 & 0.015 \\
\hline-70 & 0.029 & 0.010 & 0.010 & 0.010 & 0.038 & 0.001 & 0.058 & 0.015 \\
\hline-60 & 0.033 & 0.011 & 0.011 & 0.011 & 0.042 & 0.001 & 0.053 & 0.015 \\
\hline-50 & 0.036 & 0.012 & 0.012 & 0.012 & 0.045 & 0.001 & 0.047 & 0.015 \\
\hline-40 & 0.040 & 0.013 & 0.013 & 0.013 & 0.050 & 0.001 & 0.042 & 0.015 \\
\hline-30 & 0.043 & 0.014 & 0.014 & 0.014 & 0.054 & 0.001 & 0.036 & 0.015 \\
\hline-20 & 0.047 & 0.015 & 0.015 & 0.015 & 0.058 & 0.001 & 0.031 & 0.015 \\
\hline-10 & 0.051 & 0.017 & 0.016 & 0.017 & 0.063 & 0.001 & 0.026 & 0.015 \\
\hline 0 & 0.055 & 0.018 & 0.017 & 0.018 & 0.067 & 0.001 & 0.020 & 0.015 \\
\hline 10 & 0.059 & 0.019 & 0.018 & 0.019 & 0.072 & 0.001 & 0.017 & 0.015 \\
\hline 20 & 0.063 & 0.021 & 0.020 & 0.020 & 0.077 & 0.001 & 0.014 & 0.015 \\
\hline 30 & 0.067 & 0.022 & 0.021 & 0.022 & 0.082 & 0.001 & 0.011 & 0.015 \\
\hline 40 & 0.072 & 0.023 & 0.022 & 0.023 & 0.087 & 0.001 & 0.008 & 0.015 \\
\hline 50 & 0.077 & 0.025 & 0.024 & 0.025 & 0.092 & 0.001 & 0.005 & 0.015 \\
\hline 60 & 0.081 & 0.027 & 0.025 & 0.026 & 0.098 & 0.001 & 0.005 & 0.015 \\
\hline 70 & 0.086 & 0.028 & 0.027 & 0.027 & 0.103 & 0.001 & 0.005 & 0.015 \\
\hline 80 & 0.091 & 0.030 & 0.028 & 0.029 & 0.109 & 0.001 & 0.005 & 0.015 \\
\hline
\end{tabular}


Table 3. Combined uncertainty $u(k=1)$ of the radiation temperature of the VLTBB.

\begin{tabular}{rccccc}
\hline & \multicolumn{5}{c}{ VLTBB, combined uncertainty $u / \mathrm{K}$} \\
\cline { 2 - 6 }$t /{ }^{\circ} \mathrm{C}$ & $4.8 \mu \mathrm{m}$ & $6.7 \mu \mathrm{m}$ & $9.9 \mu \mathrm{m}$ & $12.2 \mu \mathrm{m}$ & $14.1 \mu \mathrm{m}$ \\
\hline-80 & 0.070 & 0.066 & 0.066 & 0.066 & 0.074 \\
-70 & 0.067 & 0.061 & 0.061 & 0.061 & 0.071 \\
-60 & 0.064 & 0.056 & 0.056 & 0.056 & 0.069 \\
-50 & 0.061 & 0.051 & 0.051 & 0.051 & 0.067 \\
-40 & 0.060 & 0.046 & 0.046 & 0.046 & 0.067 \\
-30 & 0.058 & 0.042 & 0.042 & 0.042 & 0.067 \\
-20 & 0.058 & 0.038 & 0.038 & 0.038 & 0.068 \\
-10 & 0.059 & 0.034 & 0.034 & 0.034 & 0.069 \\
0 & 0.060 & 0.031 & 0.030 & 0.031 & 0.072 \\
10 & 0.063 & 0.030 & 0.029 & 0.030 & 0.076 \\
20 & 0.066 & 0.029 & 0.029 & 0.029 & 0.080 \\
30 & 0.070 & 0.029 & 0.028 & 0.029 & 0.084 \\
40 & 0.074 & 0.029 & 0.028 & 0.029 & 0.089 \\
50 & 0.078 & 0.030 & 0.029 & 0.029 & 0.094 \\
60 & 0.083 & 0.031 & 0.030 & 0.030 & 0.099 \\
70 & 0.088 & 0.032 & 0.031 & 0.032 & 0.105 \\
80 & 0.093 & 0.034 & 0.033 & 0.033 & 0.110 \\
\hline
\end{tabular}

Table 4. Maximum individual deviation of the measured radiation temperature from the fitted calibration curve (fourth-power polynomial) for each PRT with the corresponding standard uncertainty $u$ of the radiation temperature measurement.

\begin{tabular}{cccccccc}
\hline \multicolumn{3}{c}{ GBB-C } & & & \multicolumn{3}{c}{ GBB-H } \\
\cline { 1 - 2 } \cline { 6 - 7 } PRT & max. dev./K & $u / K$ & & PRT & max. dev./K & $u / K$ \\
\hline S110 & 0.039 & 0.107 & & S210 & 0.010 & 0.103 \\
S111 & 0.053 & 0.103 & & S211 & 0.019 & 0.085 \\
S112 & 0.051 & 0.104 & & S212 & 0.014 & 0.095 \\
S113 & 0.046 & 0.103 & & S213 & 0.013 & 0.066 \\
S114 & 0.050 & 0.105 & & S214 & 0.020 & 0.063 \\
S120 & 0.051 & 0.103 & & S220 & 0.009 & 0.067 \\
S121 & 0.046 & 0.103 & & S221 & 0.019 & 0.068 \\
S122 & 0.044 & 0.105 & & S222 & 0.013 & 0.085 \\
S123 & 0.041 & 0.104 & & S223 & 0.016 & 0.067 \\
S124 & 0.052 & 0.103 & & S224 & 0.019 & 0.089 \\
\hline
\end{tabular}

LBB in the relevant spectral range of the GLORIA instrument at $0{ }^{\circ} \mathrm{C}$.

The VLTBB was also compared to the VMTBB at several temperatures in the temperature range from $80^{\circ} \mathrm{C}$ to $170^{\circ} \mathrm{C}$ via VIRST and via the vacuum FTS in the RBCF. All measurements showed good agreement of the radiation temperatures well within the expanded uncertainty of the comparison of $130 \mathrm{mK}$. Figure 11 gives the difference in radiation temperature of the VLTBB and the VMTBB in the relevant spectral range of the GLORIA instrument at $80^{\circ} \mathrm{C}$.

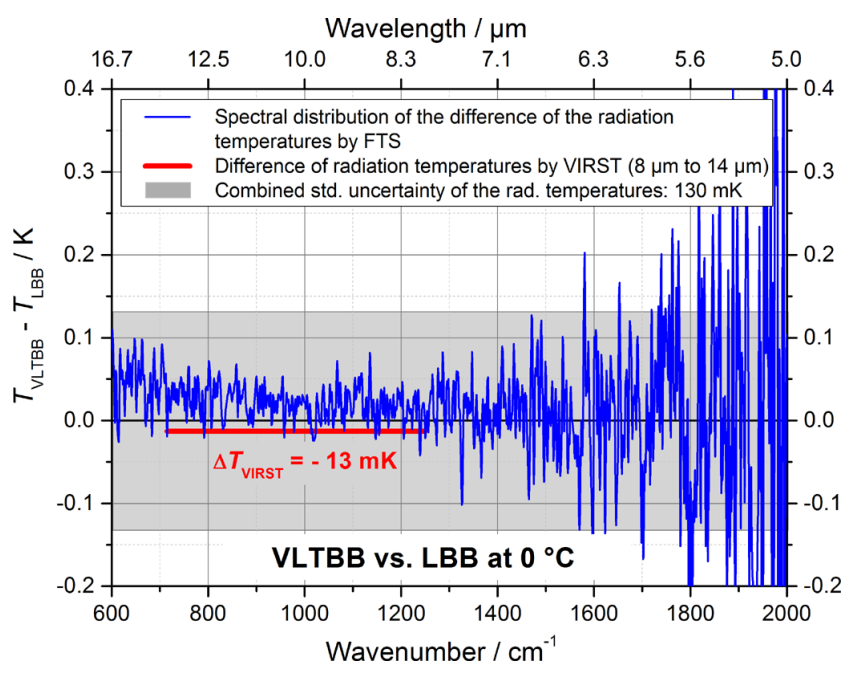

Fig. 10. Difference between the radiation temperatures of the VLTBB and the LBB at $0^{\circ} \mathrm{C}$ measured with the vacuum FTS (blue line) in the relevant wavelength range of the GLORIA instrument and with VIRST (red line) at the RBCF.

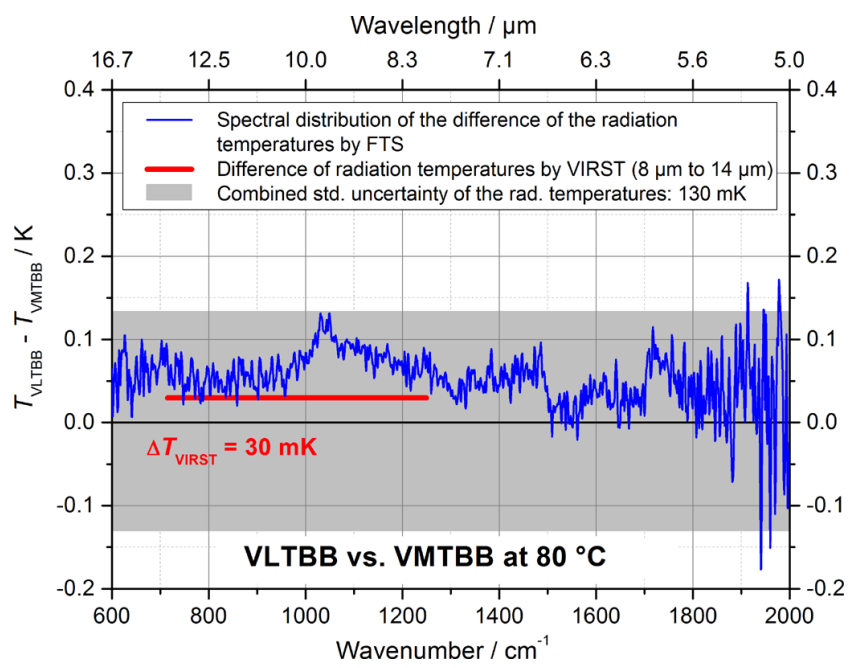

Fig. 11. Difference between the radiation temperatures of the VLTBB and the VMTBB at $80^{\circ} \mathrm{C}$ measured with the vacuum FTS (blue line) in the relevant wavelength range of the GLORIA instrument and with VIRST (red line) at the RBCF. 

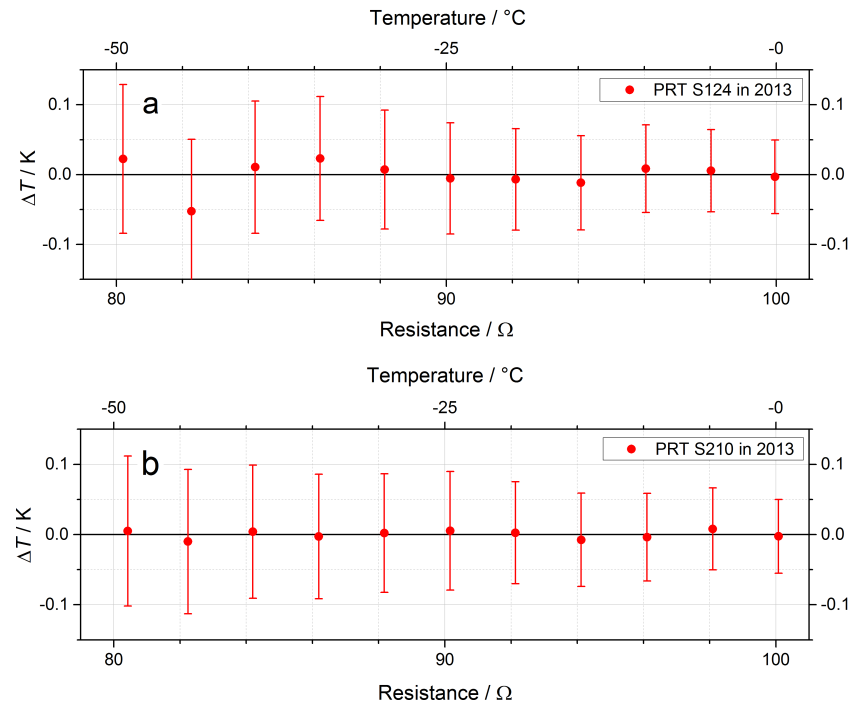

Fig. 12. Deviation (residuals) of the measured radiation temperature from the calibration curve at the measured resistance values (corresponding to temperature steps of $5{ }^{\circ} \mathrm{C}$ from $-50^{\circ} \mathrm{C}$ to $0^{\circ} \mathrm{C}$ ) for two selected PRTs. (a) PRT S124 (GBB-C), which showed the largest deviation of a calibration point from the fitted calibration curve in the January 2013 calibration campaign. (b) PRT S210 (GBB-H), which showed the smallest deviation of all calibration points from the fitted calibration curve in the January 2013 calibration campaign.

Finally, the VLTBB was compared to the ammonia heatpipe blackbody of PTB in February 2012. The ammonia heat-pipe blackbody is the primary national standard of radiation temperature from $-60{ }^{\circ} \mathrm{C}$ to $50^{\circ} \mathrm{C}$ in air at PTB (Hollandt et al., 2003/2007). It has successfully been used in several international comparisons with other national metrology institutes. For example it was compared via the instrument Absolute Measurements of Blackbody Emitted Radiance (AMBER) to the radiation temperature scale of the National Physical Laboratory (NPL), the national metrological laboratory of the United Kingdom, in June 2012 (Gutschwager et al., 2013).

The comparison between the VLTBB and the ammonia heat-pipe blackbody was performed with a compact industrial radiation thermometer of the type OPTRIS CSlaser LT hs SPEZIAL with a temperature resolution of $10 \mathrm{mK}$ in the temperature range of the comparison. A modified optics system of the radiation thermometer allowed viewing the VLTBB directly, without using a window, by attaching it to the opto-mechanical unit of the RBCF via an adjustable vacuum flange. The comparison was performed over the temperature range from $-40^{\circ} \mathrm{C}$ to $50^{\circ} \mathrm{C}$ and showed an agreement of both blackbodies ranging from a $43 \mathrm{mK}$ deviation at $50{ }^{\circ} \mathrm{C}$ to a $209 \mathrm{mK}$ deviation at $-40^{\circ} \mathrm{C}$. Thus both blackbodies agree well within the rather large extended uncertainty of this comparison. The uncertainty of this comparison, ranging from $150 \mathrm{mK}$ at $50^{\circ} \mathrm{C}$ to $400 \mathrm{mK}$ at $-40^{\circ} \mathrm{C}$, was mainly caused by the comparison instrument and the comparison procedure. Due to the fact that a blackbody operated under vacuum is compared to a blackbody operated in air, several corrections had to be performed in the comparison process. For this reason, the main contributions to the uncertainty of the comparison are the correction of the size-of-source effect of the radiation thermometer due to the different temperature environments of the blackbodies, the correction of atmospheric absorption when viewing the ammonia heat-pipe blackbody in air, the correction for changes of the internal temperature of the radiation thermometer, and the correction for a sensitivity drift of the radiation thermometer. To carefully perform these corrections, the size-of-source effect and the temperature parameter of the radiation thermometer have been determined. Possible drifts of the radiation thermometer were corrected by measuring the VLTBB between two measurements at the ammonia heat-pipe blackbody. However, the performance of the compact industrial radiation thermometer clearly limited the achievable comparison uncertainty, especially at lower temperatures. In this context it should be pointed out that the original purpose and proper task of this radiation thermometer, which is easy to transport and operate, is to enable a simple and fast comparison of the blackbodies in the RBCF with the ammonia heat-pipe blackbody near room temperature in order to detect possible long-term drifts of the PRTs of the vacuum blackbodies and help to define their recalibration intervals, a task it performs very well.

\section{Calibration results}

During three calibration campaigns the GBBs were comprehensively characterized at the RBCF in the period from December 2010 to January 2013 in terms of their radiometric and thermometric requirements summarized in Sect. 2.2.

\subsection{Radiation temperature calibration of PRTs}

For the calibration of the radiation temperature versus resistance characteristics of all 10 PRTs of each GBB the temperature of the $\mathrm{GBB}$ was changed from $-50^{\circ} \mathrm{C}$ to $0^{\circ} \mathrm{C}$ in steps of $5^{\circ} \mathrm{C}$. For each temperature, VIRST measured the radiation temperature of the optical surface at the position of the corresponding PRT while simultaneously the resistance values of the PRT were recorded. The resulting calibration points of each PRT were fitted with a fourth-power polynomial, yielding the calibration characteristic for the corresponding thermometer during the successive GBB operation in flight. In Fig. 12 two typical calibration results are presented. Here the deviations of the measured radiation temperatures from the calibration curve at the corresponding resistances of the PRTs (i.e. the residuals of the fit), including the uncertainty of each measurement, are shown. In Table 4 the maximum individual deviation of a calibration point from the fitted polynomial for each PRT during the January 2013 calibration 


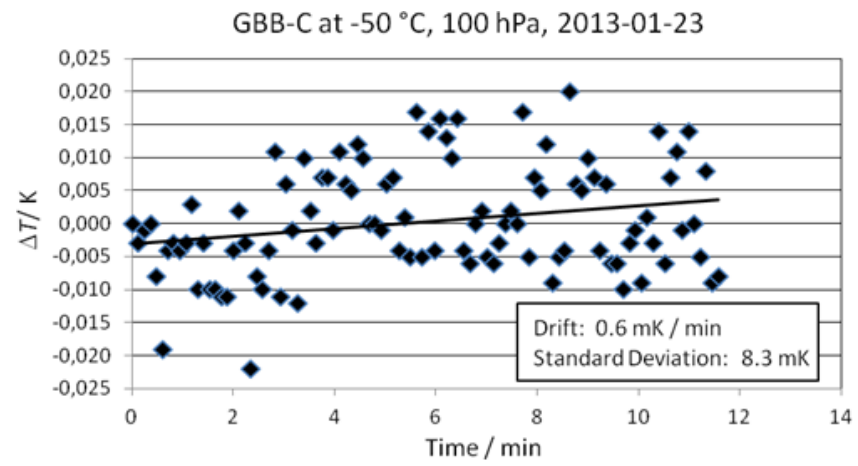

Fig. 13. Short-term stability of the radiation temperature of the GLORIA blackbody GBB-C at $-50^{\circ} \mathrm{C}$ and $100 \mathrm{hPa}$ observed in the middle of the optical surface.

campaign and the corresponding uncertainty is given. In all cases the deviations can be neglected with respect to the calibration uncertainty. In general the standard calibration uncertainty resulting from this procedure is always less than $110 \mathrm{mK}$ for all PRTs and all temperatures and therefore practically fulfills the calibration uncertainty requirements of the GBBs and meets the target requirements.

\subsection{Short-term stability}

The short-term stability of both GBBs has been measured with VIRST at several temperatures and several positions on their optical surface. All measurements confirmed that the required stability of better than $25 \mathrm{mK} \mathrm{min}^{-1}$ is achieved. Examples are given in Figs. 13 and 14.

\subsection{Temperature homogeneity}

The temperature homogeneity of both GBBs across their optical surface has been measured at several temperatures by scanning the GBBs in two dimensions through the field of view of VIRST. The two-dimensional scans were performed as a $11 \times 11$ grid with $9 \mathrm{~mm}$ step size matched to the $10 \mathrm{~mm}$ diameter of the field of view of VIRST. All measurements confirmed that the required homogeneity of better than $150 \mathrm{mK}$ over the area of the optical surface of the blackbodies observed by GLORIA is achieved. Examples showing a slightly larger area of $82 \mathrm{~mm} \times 82 \mathrm{~mm}$ are given in Figs. 15 to 17 . Herein the data recorded within the circular field of view of VIRST are depicted as full squares (left panels). For a better visualization the measured data are also shown as spline-interpolated values. To avoid artefacts the interpolation was done over the $90 \mathrm{~mm} \times 90 \mathrm{~mm}$ recorded data; however a field of $82 \mathrm{~mm} \times 82 \mathrm{~mm}$ is also shown. In this representation a slightly different temperature in the corners and the pyramid structure becomes visible.

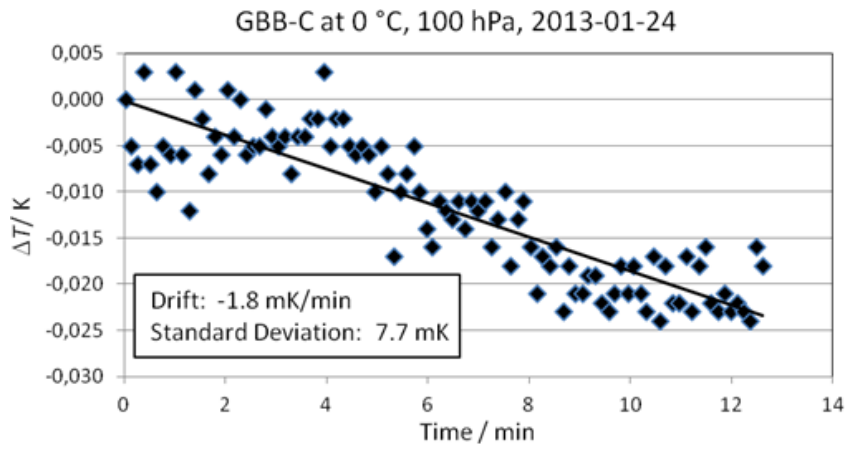

Fig. 14. Short-term stability of the radiation temperature of the GLORIA blackbody GBB-C at $0^{\circ} \mathrm{C}$ and $100 \mathrm{hPa}$ observed in the middle of the optical surface.

\subsection{Spectral radiance}

The spectrally resolved radiation temperature of both GBBs has been measured with the vacuum FTS at several temperatures and several positions of their optical surface over the full operating spectral range of GLORIA and beyond. The $18 \mathrm{~mm}$ diameter field of view of the vacuum FTS was placed at several positions of the optical surface, considering that all three different types of pyramids were alternatively observed (compare insets Figs. 18 and 19). The measured radiation temperatures showed no significant dependence on wavelength or surface position. All measurements confirmed that a high as well as spatially and spectrally homogeneous effective emissivity is achieved with the coated pyramid array. Examples from the last calibration campaign are given in Figs. 18 and 19. Similar measurements recorded during the first two calibration campaigns exhibited no significant differences.

The semitransparent areas in Figs. 18 and 19 illustrate the ranges of the combined standard uncertainty of the spectral distribution of the radiation temperatures determined at three positions of the optical surface. The uncertainty of the radiation temperature results from four contributions: the temperature stability of the GBB-H during the measurement, the homogeneity of the radiation temperature within each of the three measurement areas of the spectrally resolved measurement, the spectrally dependent uncertainty of the reference blackbody VLTBB as given in Table 3 and the type A uncertainty of the spectrometer measurements. The latter two dominate the combined uncertainty.

\subsection{Long-term stability}

The short-term stability of the radiation temperature versus resistance characteristics of all PRTs of the GBBs during laboratory calibration at the RBCF was checked several times during all three calibration campaigns and was insignificant, i.e. stayed well below the calibration uncertainty. However, special care was taken to check the stability of all 

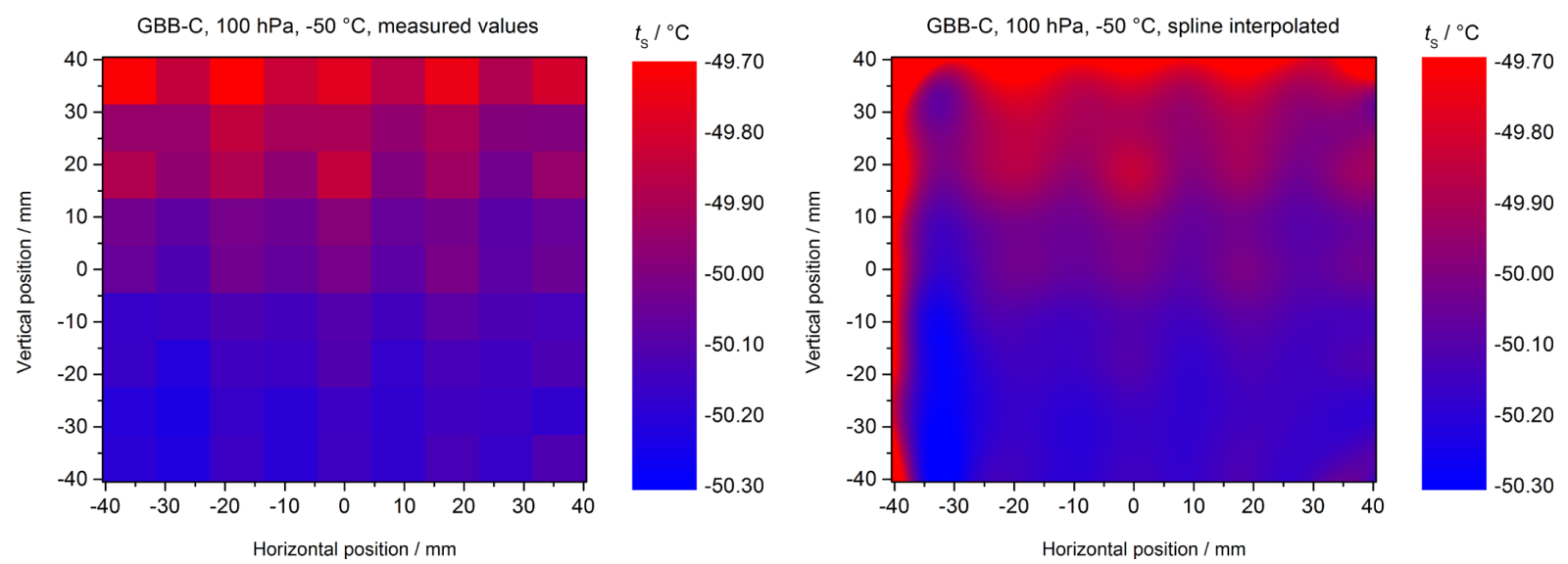

Fig. 15. The spatial distribution of the radiation temperature of the GLORIA blackbody GBB-C at a nominal temperature of $-50{ }^{\circ} \mathrm{C}$ and $100 \mathrm{hPa}$. The field of view is $82 \mathrm{~mm} \times 82 \mathrm{~mm}$. The measured data are shown on the left panel, the spline-interpolated data on the right. The homogeneity is $132 \mathrm{mK}$ (standard deviation).
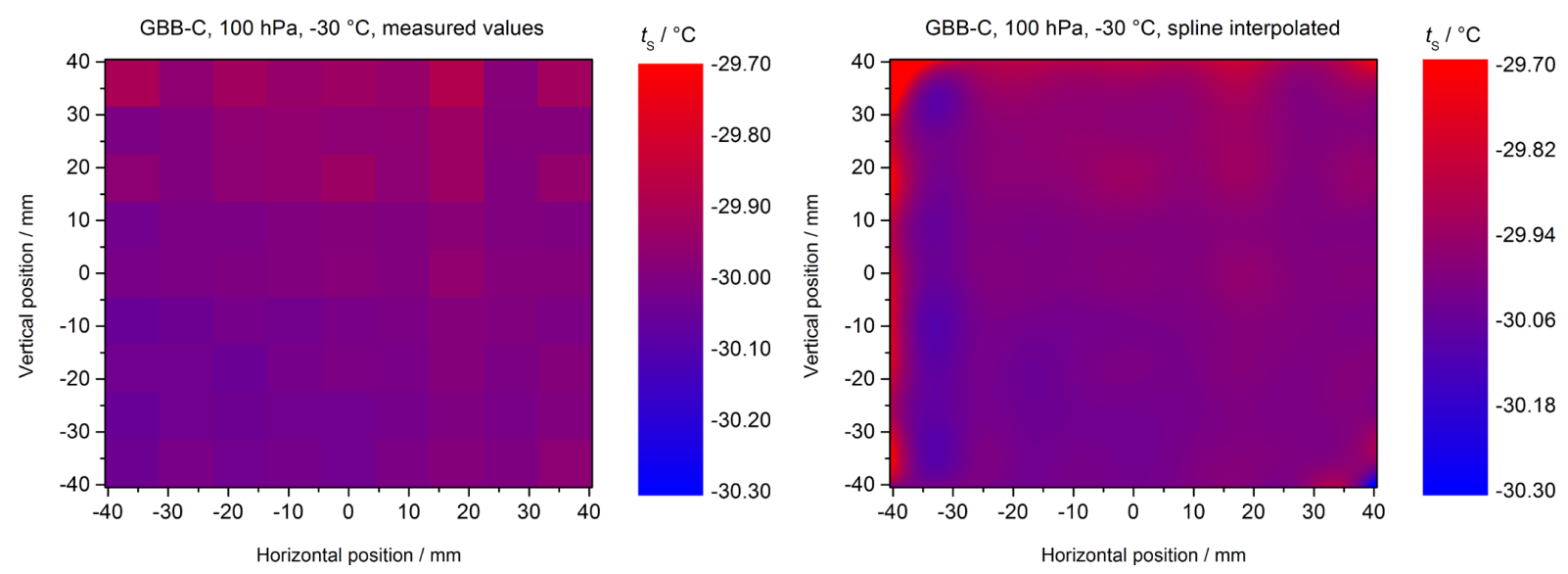

Fig. 16. The spatial distribution of the radiation temperature of the GLORIA blackbody GBB-C at a nominal temperature of $-30{ }^{\circ} \mathrm{C}$ and $100 \mathrm{hPa}$. The field of view is $82 \mathrm{~mm} \times 82 \mathrm{~mm}$. The measured data are shown on the left panel, the spline-interpolated data on the right. The homogeneity is $35 \mathrm{mK}$ (standard deviation).
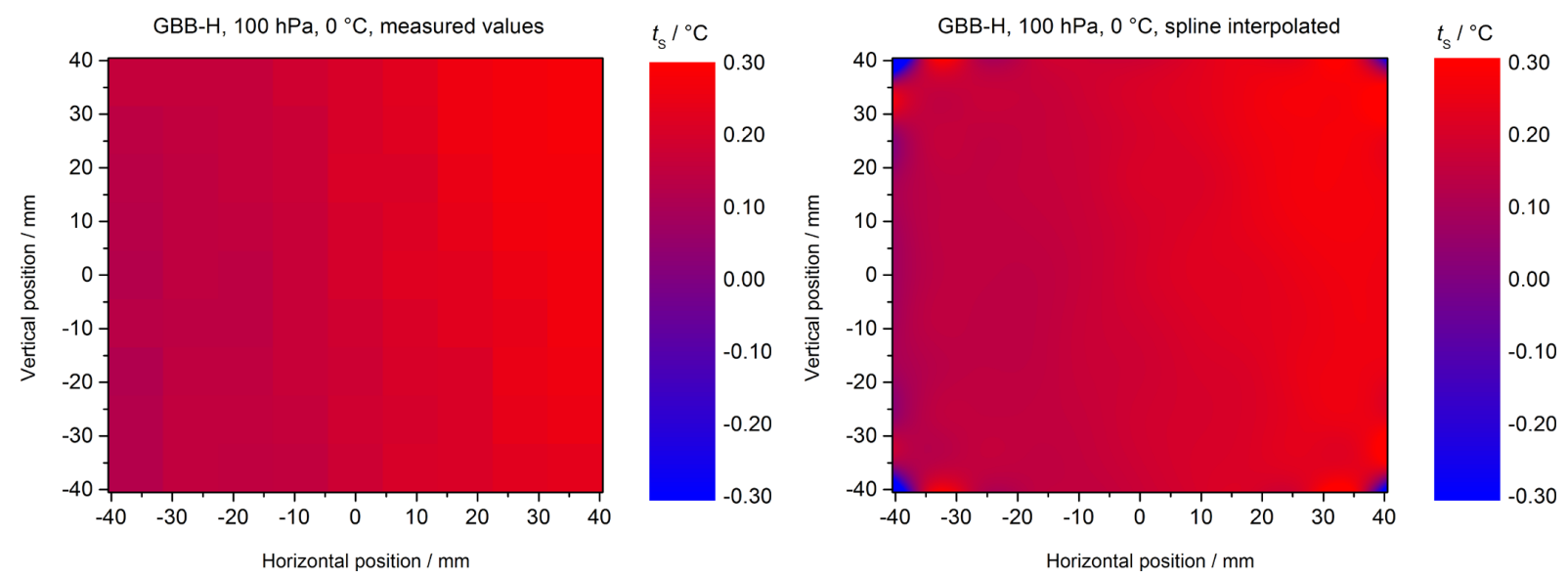

Fig. 17. The spatial distribution of the radiation temperature of the GLORIA blackbody GBB-H at a nominal temperature of $0{ }^{\circ} \mathrm{C}$ and $100 \mathrm{hPa}$. The field of view is $82 \mathrm{~mm} \times 82 \mathrm{~mm}$. The measured data are shown on the left panel, the spline-interpolated data on the right. The homogeneity is $47 \mathrm{mK}$ (standard deviation). 


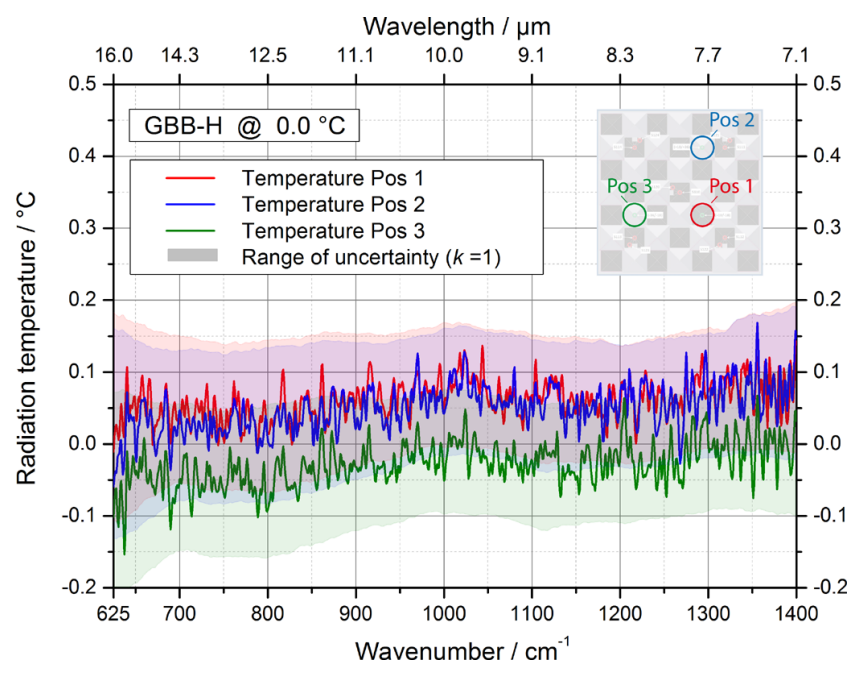

Fig. 18. The spectrally resolved radiation temperature of the GBB$\mathrm{H}$ measured with the vacuum FTS at $0^{\circ} \mathrm{C}$ and three different positions on the optical surface. The respective ranges of the measurement uncertainty are depicted as shaded areas. The three measurement areas on the optical surface of the GBB-H are shown as circles in the inset.

Table 5. Maximum individual change of the fitted calibration characteristics for each PRT between the calibration campaigns in January 2012 and January 2013. Changes of less than $170 \mathrm{mK}$ (corresponding to the target radiance uncertainty of $1 \%$ of GLORIA measurements) are shown in regular typeface, whereas changes of less than $500 \mathrm{mK}$ (corresponding to the minimum radiance uncertainty requirement of $3 \%$ of GLORIA measurements) are shown in italic typeface.

\begin{tabular}{ccccc}
\hline \multicolumn{2}{c}{ GBB-C } & & \multicolumn{2}{c}{ GBB-H } \\
\cline { 1 - 2 } \cline { 5 - 5 } PRT & max. change/K & & PRT & max. change/K \\
\hline S110 & 0.197 & & S210 & 0.053 \\
S111 & 0.228 & & S211 & 0.129 \\
S112 & 0.111 & & S212 & 0.101 \\
S113 & 0.120 & & S213 & 0.064 \\
S114 & 0.083 & & S214 & 0.108 \\
S120 & 0.231 & & S220 & 0.089 \\
S121 & 0.251 & & S221 & 0.144 \\
S122 & 0.360 & & S222 & 0.194 \\
S123 & 0.205 & & S223 & 0.155 \\
S124 & 0.178 & & S224 & 0.141 \\
\hline
\end{tabular}

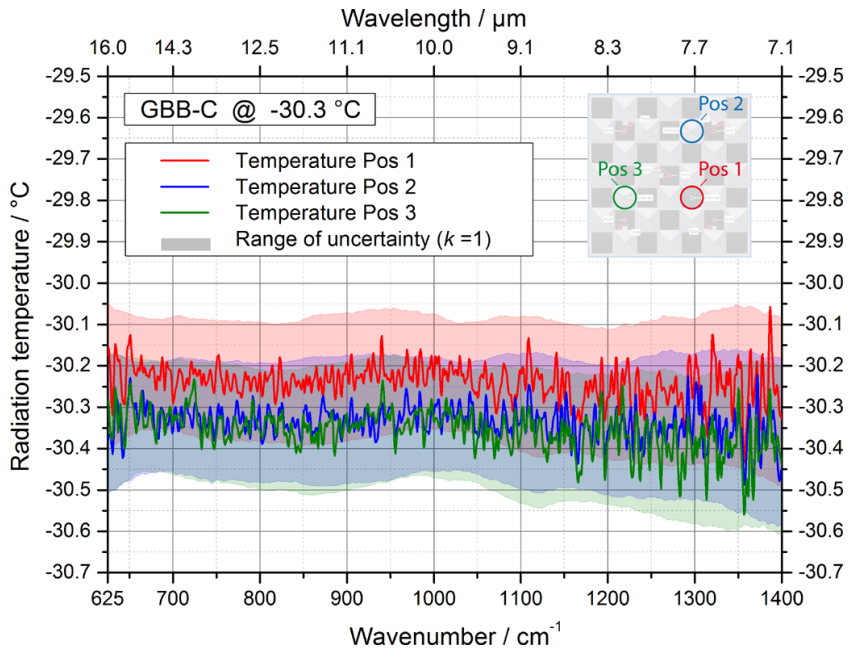

Fig. 19. The spectrally resolved radiation temperature of the GBB$\mathrm{C}$ measured with the vacuum FTS at $-30.3^{\circ} \mathrm{C}$ and three different positions on the optical surface. The respective ranges of the measurement uncertainty are depicted as shaded areas. The three measurement areas on the optical surface of the GBB-C are shown as circles in the inset.

PRTs before and after flight operation. Therefore the resulting fourth-power polynomials fitted to the calibration points before and after flight operation were compared for each PRT and the maximum deviation before and after flight recorded. Figure 20 gives two examples of PRT calibration curves before and after flight operation. Table 5 gives the maximum individual change of the fitted calibration characteristics for each PRT resulting from the January 2012 and January 2013 calibration campaigns, i.e. before and after GLORIA's first scientific campaign with HALO during the TACS/ESMVal campaign. The PRTs are grouped into two stability categories, representing the requirements: better than $1 \%$ and better than $3 \%$ of spectral radiance uncertainty, corresponding to $170 \mathrm{mK}$ and $500 \mathrm{mK}$ radiation temperature uncertainty over the full spectral range of the GBBs. Table 5 reveals that the stability of the radiation temperature versus resistance characteristics of the PRTs under the rough environment during flight operation is the major uncertainty contribution in the traceability of the GBBs to the ITS-90. To quantify and minimize this effect, contemporary calibrations of all PRTs before and after flight operation are necessary.

\section{Summary and outlook}

To ensure the traceability of the trace gas and temperature measurements of the airborne limb sounding experiment GLORIA to the International Temperature Scale and thereby to an absolute radiance scale, GLORIA carries an on-board calibration system. It basically consists of two identical large-area and high-emissivity infrared radiators, which 


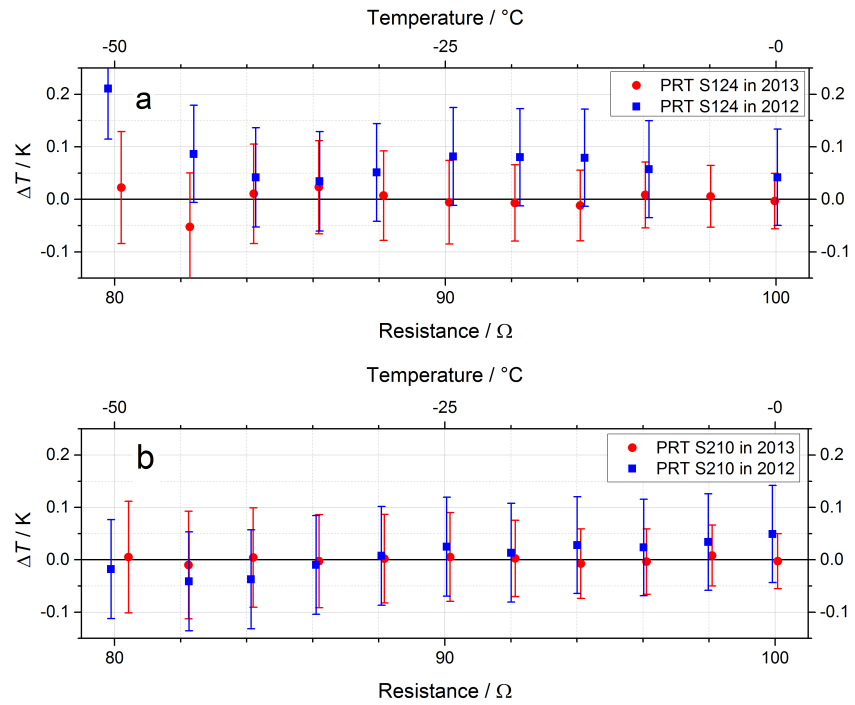

Fig. 20. The same calibration curves as in Fig. 12 are shown in red. Additionally, the deviations of the measured radiation temperatures of 2012 to the polynomial fit of 2013 are shown as a second curve in blue in each panel. (a) illustrates with PRT S124 a typical case of moderate changes, whereas (b) illustrates with PRT S210 a typical case of small changes.

can be continuously and independently operated at two adjustable temperatures in a range from $-50^{\circ} \mathrm{C}$ to $0^{\circ} \mathrm{C}$ during flight. We described the thorough radiometric and thermometric characterization and calibration of the in-flight calibration system at the Reduced Background Calibration Facility of the Physikalisch-Technische Bundesanstalt during three calibration campaigns before and after flight of the GLORIA instrument. The radiation temperature versus resistance characteristics of all 10 PRTs of each GBB have been calibrated with a standard uncertainty less than $110 \mathrm{mK}$ for all PRTs and all relevant temperatures and therefore practically fulfil the calibration uncertainty requirements of the GBBs. All measurements confirmed that the required shortterm stability of better than $25 \mathrm{mK} \mathrm{min}^{-1}$ and spatial homogeneity of better than $\pm 75 \mathrm{mK}$ over the full optical surface are achieved by both GBBs. The measured radiation temperatures showed no significant dependence on wavelength or surface position. All measurements confirmed that a high as well as spatially and spectrally homogeneous effective emissivity is achieved with the coated pyramid array. So in general the target requirements for the calibration are met. Only in the case of the long-term stability of part of the PRTs of one blackbody are the minimum requirements met. The GLORIA calibration system will be regularly linked to the ITS-90 via the Reduced Background Calibration Facility at PTB to provide traceability of the GLORIA atmospheric measurements as needed.

The achieved spatial temperature homogeneity, which fully complies with the requirements, can be further im- proved by modifying the temperature control software. Although four independent TEC control circuits for the four sectors of the pyramid array are already implemented, currently only one single temperature set point value for all four sectors is freely selectable. Performance can further be improved by reducing the thermal mass of the optical surface. A new design of the pyramid array with an increased number of significantly smaller pyramids, which retains the advantage of the steep pyramid angles, is envisaged. In future designs the usage of removable thermally treated and individually selected PTR sensors, which are calibrated as contact thermometers at a $30 \mathrm{mK}$ uncertainty level, is desired. Based on the experience with the airborne blackbodies, a balloonborne calibration source will be developed.

Acknowledgements. The authors wish to thank Marco Schulz and Max Reiniger for their valuable technical support during the measurements at the RBCF.

Part of this work has been supported by the European Metrology Research Programme (EMRP) within the joint research project Metrology for Earth Observation and Climate (MetEOC). The EMRP is jointly funded by the EMRP participating countries within EURAMET and the European Union.

The financial support of the Institute for Energy and Climate Research: Stratosphere (IEK-7) at Forschungszentrum Jülich $\mathrm{GmbH}$ for the design of the GLORIA blackbodies as part of the GLORIA project is gratefully acknowledged.

Edited by: J. Notholt

\section{References}

ESA: Candidate Earth Explorer Core Missions - Report for Assessment: PREMIER - PRocess Exploitation through Measurements of Infrared and millimetre-wave Emitted Radiation, Vol. SP-1313/5, ESA Publications Division, ESTEC, Keplerlaan 1, 2200 AG Noordwijk, the Netherlands, 2008.

ESA: Report for mission selection: PREMIER, Vol. SP-1324/3, ESA Publications Division, ESTEC, Keplerlaan 1, 2200 AG Noordwijk, the Netherlands, 2012.

Friedl-Vallon, F., Gulde, T., Hase, F., Kleinert, A., Kulessa, T., Maucher, G., Neubert, T., Olschewski, F., Piesch, C., Preusse, P., Rongen, H., Sartorius, C., Schneider, H., Schönfeld, A., Tan, V., Bayer, N., Blank, J., Dapp, R., Ebersoldt, A., Fischer, H., Guggenmoser, T., Höpfner, M., Kaufmann, M., Kretschmer E., Nordmeyer, H., Oelhaf, H., Orphal, J., Riese, M., Schardt, G., Schillings, J., Sha, M. K., Suminska-Ebersoldt, O., and Ungermann, J.: Instrument concept of the imaging Fourier transform spectrometer GLORIA, Atmos. Meas. Tech., in preparation, 2014

Gutschwager, B., Hollandt, J., Jankowski, T., and Gärtner, R.: Vacuum Infrared Standard Radiation Thermometer at the PTB, Int. J. Thermophys., 29, 330-340, 2008. 
Gutschwager, B., Gärtner, R., and Hollandt, J.: An Infrared Precision Radiation Thermometer for the Calibration of Remote Sensing Instrumentations under Vacuum, in: Image and Signal Processing for Remote Sensing XV, edited by: Bruzzone, L., Notarnicola, C., and Posa, F., Vol. 7477, Proceedings of SPIE/, 747719, Berlin, 2009.

Gutschwager, B., Theocharous, E., Monte, C., Adibekyan, A., Reiniger, M., Fox, N. P., and Hollandt, J.: Comparison of the radiation temperature scales of the PTB and the NPL in the temperature range from $-57^{\circ} \mathrm{C}$ to $50^{\circ} \mathrm{C}$, Measurement Sci. Technol., 24, 065002.1-065002.9, 2013.

Hollandt, J., Friedrich, R., Gutschwager, B., Taubert, D. R., and Hartmann, J.: High-accuracy radiation thermometry at the National Metrology Institute of Germany, the PTB, High Temp. High Press., 35/36, 379-415, 2003/2007.

Howell, J. R.: A catalog of radiation heat transfer configuration factors, available at: http://www.engr.uky.edu/rtl/Catalog/ (last access: May 2013), 2010.

Joint Committee for Guides in Metrology (JCGM): Evaluation of measurement data - Guide to the expression of uncertainty in measurement, BIPM, 2008.

Lohrengel, J. and Todtenhaupt, R.: Wärmeleitfähigkeit, Gesamtemissionsgrade und spektrale Emissionsgrade der Beschichtung Nextel-Velvet-Coating 811-21 (RAL 90015 tiefschwarz matt), PTB-Mitteilungen, 106, 259-265, 1996.

Monte, C. and Hollandt, J.: The determination of the uncertainties of spectral emissivity measurements in air at the PTB, Metrologia, 47, S172-S181, 2010a.

Monte, C. and Hollandt, J.: The Measurement of Directional Spectral Emissivity in the Temperature Range from $80^{\circ} \mathrm{C}$ to $400^{\circ} \mathrm{C}$ at the Physikalisch-Technische Bundesanstalt, High Temp. - High Press., 39, 151-164, 2010b.

Monte, C., Gutschwager, B., and Hollandt, J.: The Reduced Background Calibration Facility for Detectors and Radiators at the Physikalisch-Technische Bundesanstalt, in: Sensors, Systems, and Next-Generation Satellites XIII, edited by: Meynart, R., Neeck, S. P., and Shimoda, H., Vol. 7474, Proceedings of SPIE/, 747414, Berlin, 2009a.

Monte, C., Gutschwager, B., Morozova, S., and Hollandt, J.: Radiation Thermometry and Emissivity Measurements under Vacuum at the PTB, Int. J. Thermophys., 30, 203-219, 2009 b.

Monte, C., Gutschwager, B., Adibekyan, A., Kehrt, M., Olschewski, F., and Hollandt, J.: Radiation Thermometry for Remote Sensing at PTB, in: Proceedings 9th International Temperature Symposium (ITS-9), 2013.
Morozova, S., Parfentiev, N., Lisiansky, B. E., Sapritsky, V. I., Dovgilov, N. L., Melenevsky, U. A., Gutschwager, B., Monte, C., and Hollandt, J.: Vacuum Variable Temperature Blackbody VLTBB100, Int. J. Thermophys., 29, 341-351, 2008.

Morozova, S. P., Parfentiev, N. A., Lisiansky, B. E., Melenevsky, U., Gutschwager, B., Monte, C., and Hollandt, J.: Vacuum Variable Medium Temperature Blackbody (VMTBB), Int. J. Thermophys., 31, 1809-1820, 2010.

Olschewski, F., Ebersoldt, A., Friedl-Vallon, F., Gutschwager, B., Hollandt, J., Kleinert, A., Monte, C., Piesch, C., Preusse, P., Rolf, C., Steffens, P., and Koppmann, R.: The in-flight blackbody calibration system for the GLORIA interferometer on board an airborne research platform, Atmos. Meas. Tech., 6, 3067-3082, doi:10.5194/amt-6-3067-2013, 2013.

Prokhorov, A. V.: Monte Carlo method in optical radiometry, Metrologia, 35, 465-471, 1998.

Prokhorov, A.: Blackbody emissivity modeling software STEEP320, available at: http://www.virial.com/steep320.html (last access: May 2013), 2013.

Riese, M., Ploeger, F., Rap, A., Vogel, B., Konopka, P., Dameris, M., and Forster, P.: Impact of uncertainties in atmospheric mixing on simulated UTLS composition and related radiative effects, J. Geophys. Res., 117, 1-10, 2012.

Riese, M., Preusse, P., Oelhaf, H., Friedl-Vallon, F., Hoepfner, M., Hoor, P., Kaufmann, M., Orphal, J., Ploeger, F., Spang, R., Ungermann, J., Vogel, B., and Woiwode, W.: The Gimballed Limb Observer for Radiance Imaging of the Atmosphere (GLORIA): Scientific Objectives, Atmos. Meas. Tech., in preparation, 2014.

Solomon, S., Rosenlof, K. H., Portmann, R. W., Daniel, J. S., Davis, S. M., Sanford, T. J., and Plattner, G.-K.: Contributions of Stratospheric Water Vapor to Decadal Changes in the Rate of Global Warming, Science, 327, 1219-1223, 2010.

Ungermann, J., Blank, J., Lotz, J., Leppkes, K., Hoffmann, L., Guggenmoser, T., Kaufmann, M., Preusse, P., Naumann, U., and Riese, M.: A 3-D tomographic retrieval approach with advection compensation for the air-borne limb-imager GLORIA, Atmos. Meas. Tech., 4, 2509-2529, doi:10.5194/amt-4-2509-2011, 2011. 